\title{
Growth Responses of External Hyphae of Arbuscular Mycorrhizal Fungi to Acidic Soil Conditions and their Effects on Cowpea Growth
}

\author{
AGUS ROHYADI
}

\author{
Faculty of Agriculture, Universitas Mataram, Jalan Majapahit 62, Mataram 83125, Indonesia
}

Phone: +62-370-621435, Fax: +62-370-640189, E-mail: arohyadi01@telkom.net

\begin{abstract}
The effectiveness of arbuscular mycorrhizal (AM) fungi has often been attributed to growth of their external hyphae, whilst the hyphae themselves may be subjected to the effects of severe soil conditions. The growth of external hyphae of Gigaspora margarita and Glomus etunicatum and their functions in cowpea growth have been studied at low soil $\mathrm{pH}$ using a pot system making is possible for the hyphae to grow separately from their host's roots. Pots had two compartments, one for roots (RC) and one for hyphae (HC). The RC was a cylindrical bag made of $30 \mu \mathrm{m}$ nylon mesh that retains the roots but allows the hyphae to pass through, placed centrally and surrounded by the HC. Initially, the RC was filled with $120 \mathrm{~g}$ of a soil/sand mixture (pH 5.3), inoculated with G. margarita, G. etunicatum or free fungal inoculants. A pre-germinated cowpea seed was grown in the compartment for two weeks before the $\mathrm{HC}$ was filled with $580 \mathrm{~g}$ of the mix in which the $\mathrm{pH}$ had been adjusted to 4.6, 4.9 or 5.2. Growth of the plants and of the fungal hyphae in the HC was assessed 6 weeks later. The two fungi differed in their responses to soil $\mathrm{pH}$ levels in their growth of external hyphae although they colonized plant

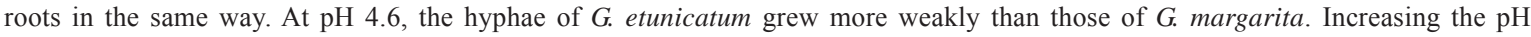
enhanced the growth of $G$. etunicatum's hyphae but reduced G. margarita's. In relation to their external hyphal functions, G. margarita was able to improve its shoot dry weight and P uptake of cowpea plants higher than G. etunicatum. These findings highlight the ability of developing an extensive external hyphal network under adverse conditions of excessive $\mathrm{H}^{+}$ions as an important characteristic for the effectiveness of AM fungi in acidic soils.
\end{abstract}

Key words: acid soils, arbuscular mycorrhiza, cowpea, external hyphae, Gigaspora margarita, Glomus etunicatum

Arbuscular mycorrhizal (AM) fungi, members of phylum Glomeromycota (Schüßler et al. 2001), establish mutual symbioses with the majority of terrestrial plant species under a wide range of soil conditions. The role of the fungi as plant growth promoters is widely recognized. They contribute to plant growth by employing their hyphae in soil to enhance the uptake of nutrient elements, especially phosphorus (P) that often increases plant growth. Generally, plants in symbiosis grow better than those without it, with the greatest effect on plants growing in marginal soils, particularly those deficient in $\mathrm{P}$, and on plant species lacking inherent morphological and physiological mechanisms for efficient P uptake (Manjunath and Habte 1991). It is thought that the presence of AM can be of great importance to enable plants to withstand severe soil conditions such as those found in acid soils $(\mathrm{pH}<5.0)$, in which toxicity of excessive $\mathrm{H}^{+}$ions per se and various limiting factors relating to the low $\mathrm{pH}$ such as deficiency and/or toxicity of some mineral elements exists (Marschner 1991). Improved growth of some crop species by AM in their soils has been reported recently, such as cowpea, maize, and soybean (Yost and Fox 1979; Rohyadi et al. 1988; Nurlaeny et al. 1996; Clark and Zeto 2000).

The beneficial effects of AM symbioses in acid soils varies considerably with fungal species and even isolates within a species (Clark and Zeto 2000; Clark 2002), and their preferences to optimum soil $\mathrm{pH}$ are considered as the main factor influencing their symbiotic effectiveness (Wilson 1988). Despite this, species or isolates preferring the same soil $\mathrm{pH}$ can also have different effects on their host plants. For example, two AM fungi, Gigaspora margarita and Glomus etunicatum, previously reported to be favored by acidic soil conditions (Borie and Rubio 1999; Clark 2002), showed differential effectiveness in increasing cowpea growth at soil $\mathrm{pH}$ 4.7-5.2; with the former being more effective than the latter (Rohyadi et al. 2004). This is thought to correspond with the capacity of these fungi to produce an extensive network of external hyphae in the soil, but since there are no measurement on the hyphae reported this hypothesis needs further elucidation.

The functions of fungal hyphae growing out from colonized roots in a symbiotic relationship have been well documented. Besides serving as the main inoculants for new root colonization, the external hyphae mainly serve as an extension of the root system that enhances plant access to water and nutrients in bulk soils outlying from depleted root zones. Despite this importance, only few observations have been carried out on the hyphae present in acidic soils so far due to problems in appropriate methods (Van Aarle et al. 2002). Hence, how they interact with adverse conditions there remains a question. Exposure to some acidity-related factors may be detrimental to the hyphae.

This paper presents results of an experiment aimed at studying the influence of low soil $\mathrm{pH}$, in terms of excessive $\mathrm{H}^{+}$ion activities, on the growth of the external hyphae of G. margarita and G. etunicatum and their function in the growth and in $\mathrm{P}$ uptake in cowpea plants.

\section{MATERIALS AND METHODS}

Experimental Pot System. In this experiment pots were designed (Fig 1) to enable external hyphae of AM fungi to grow separately from their host plant roots. Each pot had two compartments, one for RC and one for fungal $\mathrm{HC}$. The $\mathrm{RC}$ was a cylindrical bag $(3 \mathrm{~cm}$ diameter, $8 \mathrm{~cm}$ high) made up of $30 \mu \mathrm{m}$ nylon mesh that retains roots but allows hyphae to pass through, placed centrally such that it is surrounded by the HC. The significance of using this pot system was to: firstly, to allow the set-up of different treatments of soil conditions for roots and external hyphae; and secondly, to 

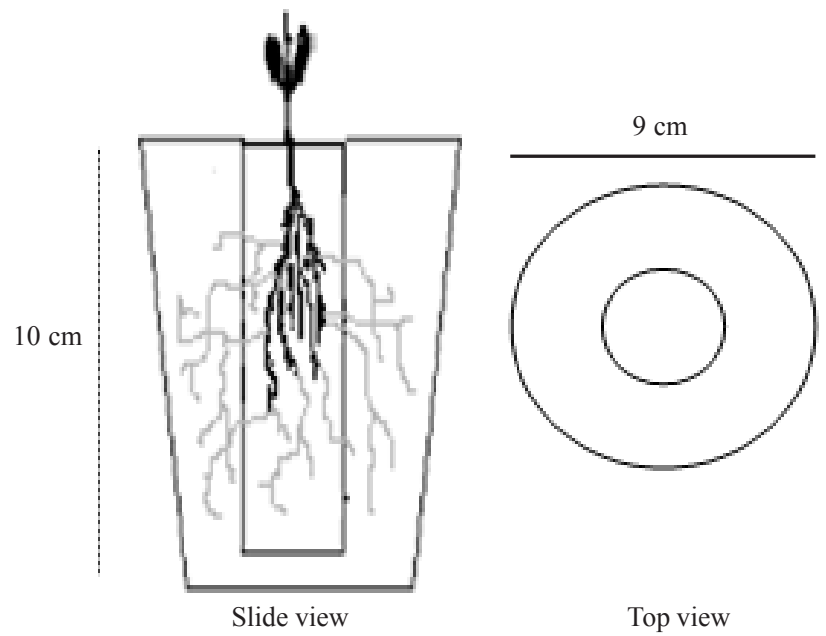

Fig 1 Overview of the pot system with two compartments for plant $\mathrm{RC}$ and external fungal $\mathrm{HC}$. The RC was a cylindrical bag made of $30 \mu \mathrm{m}$ nylon mesh.

limit the access of roots to soil resources in the RC and simultaneously to permit hyphae growing out from infected roots to develop and interact with soil conditions with different $\mathrm{pH}$ levels in the $\mathrm{HC}$, thereby contributing maximally to the growth of the host plants. Therefore, differences in plant responses to mycorrhiza were assumed to be the consequence of the functioning of the hyphae developing in the HC.

The experiment comprised three levels of mycorrhizal inoculation with and without G. margarita, G. etunicatum fungal inoculants, placed in the RC; and three levels of soil $\mathrm{pH}$ of $4.6,4.9$, and 5.2 in the HC. The treatments were arranged in a completely randomized design with four replicates. Pots without plants or inoculants were included to check changes in $\mathrm{pH}$ of growth media during the experiment.

Biological Materials. The fungi used were G. margarita Becker and Hall (BEG 34) and G. etunicatum Becker and Gerdemann (UT316-9, INVAM collection), supplied by the Laboratory of Soil Biology, The University of Adelaide, Waite Campus, South Australia. Previous work showed that both G. margarita and G. etunicatum were superior in acidic conditions (Clark 1997; Clark 2002; Borie and Rubio 1999). These isolates were raised in pot cultures of subterrainean clover (Trifolium subterranean L.) in a sand and soil mixture (90:10 w/w) for 4 months. Another set of pot cultures without these fungi was prepared similarly to provide a mycorrhizafree control. The plant used was the cowpea cv Red Caloona supplied by CSIRO Department of Tropical Agriculture, Brisbane, Australia.

Growth Medium. The growth medium was a 10:90 (w/w) mixture of soil and washed sand. The original soil was an acidic podzolic soil ( $\mathrm{a} \mathrm{pH}_{\mathrm{H} 2 \mathrm{O}}$ of 4.9); a cultivated, grey sandy loam collected from the Flaxley Farm, in the Adelaide Hills, South Australia. It was taken from $25 \mathrm{~cm}$ deep, air-dried; ground and sieved $5 \mathrm{~mm}$ mesh and then completely mixed with washed sand. The mixture is referred to as 'soil' hereafter. It was first fertilized in with $59.4 \mathrm{mg} \mathrm{NH}_{4}-\mathrm{N}, 178.2 \mathrm{mg} \mathrm{NO}_{3}-\mathrm{N}$, 36.0 mg P, 54.0 mg S, 214.2 mg K, $18.9 \mathrm{mg} \mathrm{Mg,} 114.3 \mathrm{mg} \mathrm{Ca}$,
$13.5 \mathrm{mg} \mathrm{Na}, 8.1 \mathrm{mgCl}, 2.7 \mathrm{mg} \mathrm{Fe}, 0.45 \mathrm{mg} \mathrm{B}, 0.45 \mathrm{mg} \mathrm{Mn}, 0.45 \mathrm{mg}$ $\mathrm{Zn}, 0.036 \mathrm{mg} \mathrm{Cu}$ and $0.009 \mathrm{Mo} \mathrm{mg} \mathrm{kg}^{-1}$ soil, as given in Ruakura solution (Smith et al. 1983). The soil had a final pH 5.3 and was denoted as $\mathrm{M}_{0}$. After incubation for a week, different volumes of $\mathrm{H}_{2} \mathrm{SO}_{4}$ and/or $\mathrm{NaOH}$ solutions were added to adjust the soil $\mathrm{pH}$ to $4.6,4.9$ or 5.2. The result and soils were denoted as $M_{1}, M_{2}$ or $M_{3}$ respectively. The adjustment of the $\mathrm{pH}$ and some chemical properties of these soils followed the procedures described by Rohyadi (2003). The status of some macronutrients in these soils was quite similar, while the concentrations of soluble aluminium ranged from 0.4 to 1.1 $\mu \mathrm{g} \mathrm{Al}{ }^{3+} \mathrm{g}^{-1}$ soil [measured by the method of Close and Powel (1989)], which were sub-toxic to the AM fungi tested (Rohyadi 2003). Therefore, using this experimental set up the interfering effect of toxic $\mathrm{Al}$ is minimized, so that variation induced by these fungi could be attributed to the soil $\mathrm{pH}$ per se in terms of $\mathrm{H}^{+}$ion concentrations. Lastly, these soils were autoclaved at $121^{\circ} \mathrm{C}$ for two periods of $1 \mathrm{~h}$, separated by one day intervals prior to use.

Experimental Procedures. Growth medium $\mathrm{M}_{0}$ and pot culture inoculants (with G. margarita, G. etunicatum or without these fungi), in a 90:10 (w/w) ratio, were mixed thoroughly and $120 \mathrm{~g}$ of each mix was placed into the RC. After moistening with reverse-osmosis-treated (RO) water to field capacity $\left(0.1 \mathrm{~g}\right.$ water $\mathrm{g}^{-1}$ soil $)$, a single pre-germinated cowpea seed was then grown in the compartment for 2 weeks prior to the $\mathrm{HC}$ being filled with $580 \mathrm{~g}$ of $\mathrm{M}_{1}, \mathrm{M}_{2}$ or $\mathrm{M}_{3}$ soil. Therefore, plant roots and external fungal hyphae were grown in different acidic soil conditions. The plants were maintained in a greenhouse at an average temperature of $28^{\circ} \mathrm{C}$ during the day and $19^{\circ} \mathrm{C}$ at night. During the experiment, soil moisture was maintained at field capacity by watering the $\mathrm{RC}$ with $\mathrm{RO}$ water, and the $\mathrm{HC}$ with $\mathrm{RO}$ water adjusted a $\mathrm{pH}$ $4.6,4.9$ or 5.2 . They were harvested 6 weeks later by separating plant shoots from the roots. The shoots were then dried at $70^{\circ} \mathrm{C}$ for $48 \mathrm{~h}$ and weighed. Further, the dried shoots were ground and digested using a $6: 1(\mathrm{v} / \mathrm{v})$ mixture of nitric and perchloric acids, and $\mathrm{P}$ concentration in the digest was measured (Rayment and Higginson 1992) with a Shimadzu UV-1601 spectrophotometer. Roots were carefully pulled out from the pots, washed under a stream of water, blotted dry and then weighed to determine fresh weight. Root samples were taken randomly, and after staining with trypan blue (Phillips and Hayman 1970), the root length and the mycorrhizal colonized root length (MCRL) was assessed using the Gridline-intersect method of Giovannetti and Mosse (1980).

For assessing growth of fungal hyphae in the HC, representative samples of soil in the $\mathrm{HC}$ were collected and air-dried. The assessment used the aqueous extraction and membrane-filter- technique modified as described by Rohyadi (2006). The growth was expressed as hyphal length density (HLD) counted in meter $\mathrm{g}^{-1}$ soil and in meter $\mathrm{cm}^{-1}$ MCRL.

Mycorrhizal growth responses (MGR) and mycorrhizal P-uptake responses (MPR) expressing the functioning of the external fungal hyphae in plant growth and $\mathrm{P}$ uptake, were measured using following formulae (Rohyadi et al. 2004): 


$$
\begin{aligned}
& \% M G R=\frac{S_{d w}(M) i j-S_{m / d w}(N M) j}{S_{m / d w}(N M) j} \times 100 \\
& \% \mathrm{MPR}=\frac{\mathrm{SP} \text { cont. }(\mathrm{M}) \mathrm{ij}-\mathrm{SP}_{\mathrm{m} / \mathrm{cont} .}(\mathrm{NM}) \mathrm{j}}{\mathrm{SP} \mathrm{m} / \mathrm{cont.} \text { (NM)j }} \times 100
\end{aligned}
$$

where:

$\mathrm{S}_{\mathrm{dw}}(\mathrm{M}) \mathrm{ij}$ : shoot dry weight of plants colonized by a fungus (i) at a $\mathrm{pH}$ level tested (j)

$\mathrm{S}_{\mathrm{m} / \mathrm{dw}}(\mathrm{NM}) \mathrm{j}$ : mean of shoot dry weight of non-mycorrhizal (control) plants at a $\mathrm{pH}$ level tested (j)

$\mathrm{SP}_{\text {cont. }}(\mathrm{M}) \mathrm{ij}$ : shoot $\mathrm{P}$ content of plants colonized by a fungus at a $\mathrm{pH}$ level tested

$\mathrm{SP}_{\mathrm{m} / \mathrm{cont}}(\mathrm{NM}) \mathrm{j}$ : mean of shoot $\mathrm{P}$ content of nonmycorrhizal (control) plants at a $\mathrm{pH}$ level tested

Data were analyzed using analysis of variance followed by LSD-test for significant treatments at $\mathrm{p}<0.05$.

\section{RESULTS}

Change in Soil pH. There was no significant change in soil $\mathrm{pH}$ measured after experiment (data not shown). The only decline of about 0.014 units, was observed for the control pots at $\mathrm{pH}$ 4.6.

Root Length, Mycorrhizal Colonization, and External Hyphal Growth. There was no significant effect of mycorrhizal inoculation on the growth of plant roots irrespective of soil $\mathrm{pH}$ in the HC. However, changes in the soil $\mathrm{pH}$ in terms of increasing its level to above $\mathrm{pH} 4.6$ stimulated root elongation. No mycorrhizal colonization was observed of roots of control plants. Meanwhile, both the length and percentage of roots colonized by $G$. margarita and $G$. etunicatum were not significantly different (Table 1).
The two test fungi grew external hyphae out from the colonized roots into the HC. Growth of the hyphae was significantly affected by the $\mathrm{HC}$ soil $\mathrm{pH}$ with different trends (Table 1). Increasing the $\mathrm{pH}$ from 4.6 to 4.9 and then to 5.2 steadily decreased G. margarita's hyphal growth, but it significantly increased G. etunicatum's. In general, however, compared to that of $G$. etunicatum, the hyphal length density (HLD) of G. margarita, either expression in $\mathrm{g}^{-1}$ soil or in $\mathrm{cm}^{-1}$ MCRL, was higher (particularly at $\mathrm{pH} 4.6$ ) by two or three times respectively.

Plant Growth and Responses to Mycorrhiza. Inoculation with the two fungi increased the growth of cowpea plants, although its effect depended on fungal isolates and the $\mathrm{HC}$ soil $\mathrm{pH}$. Control plants with no-mycorrhiza grew poorly regardless of the soil $\mathrm{pH}$ compared to those inoculated with G. margarita. Whilst growth of $G$. etunicatum inoculated plants was also poor at $\mathrm{pH} 4.6$, it improved as the $\mathrm{pH}$ increased. Similarly, mycorrhizal inoculation improved shoot-P concentrations, which together with increased shoot growth increased $\mathrm{P}$ uptake by the mycorrhizal colonized plants (Table 2).

Table 2 also shows the same trends for mycorrhizal contributions of these fungi to plant growth and $\mathrm{P}$ uptake, expressed as MGR and MPR. Increasing soil $\mathrm{pH}$ from 4.6 to 5.2 decreased the MGR and MPR to G. margarita, but increased both responses to G. etunicatum.

The data in Fig 2 shows extent of the mycorrhizal contributions appears to be in line with the growth of external fungal hyphae in the HC. However, patterns were different between the two fungal isolates. Inhibition of growth of $G$. margarita's external hyphae by increasing soil $\mathrm{pH}$ corresponded to the reduction in both in the MGR and the MPR of their host plants (Fig 2a). In contrast, increased growth of G. etunicatum's increased their host plant growth and P-uptake responses (Fig 2b).

Table 1 Growth and colonization of roots of cowpea plants in the RC and growth of external hyphae of G. margarita and G. etunicatum at different

\begin{tabular}{|c|c|c|c|c|c|c|}
\hline \multirow{2}{*}{$\begin{array}{c}\text { Initial soil } \\
\mathrm{pH}\end{array}$} & \multirow{2}{*}{ Inoculation } & \multirow{2}{*}{$\begin{array}{l}\text { Root length } \\
\text { (m/plant) }\end{array}$} & \multirow{2}{*}{$\begin{array}{c}\text { Mycorrhizal } \\
\text { colonization }(\%)\end{array}$} & \multirow{2}{*}{$\begin{array}{c}\text { MCRL } \\
\text { (m/plant) }\end{array}$} & \multicolumn{2}{|c|}{ Hyphal length density } \\
\hline & & & & & $\left(\mathrm{m} \mathrm{g}^{-1}\right.$ soil $)$ & $\left(\mathrm{m} \mathrm{cm}^{-1} \mathrm{MCRL}\right)$ \\
\hline \multirow[t]{3}{*}{4.6} & NM & $4.73^{\left.b^{*}\right)}$ & nd & nd & nd & nd \\
\hline & Gi. margarita & $4.86^{\mathrm{ab}}$ & $49^{\mathrm{a}}$ & $2.38^{\mathrm{ab}}$ & $3.14^{\mathrm{a}}$ & $6.92^{\mathrm{a}}$ \\
\hline & G. etunicatum & $4.71^{\mathrm{b}}$ & $46^{\mathrm{a}}$ & $2.16^{\mathrm{b}}$ & $0.98^{\mathrm{e}}$ & $2.52^{\mathrm{c}}$ \\
\hline \multirow[t]{3}{*}{4.9} & NM & $4.88^{\mathrm{ab}}$ & nd & nd & nd & nd \\
\hline & Gi. margarita & $5.04^{\mathrm{a}}$ & $53^{\mathrm{a}}$ & $2.62^{\mathrm{a}}$ & $2.65^{\mathrm{b}}$ & $6.55^{\mathrm{a}}$ \\
\hline & G. etunicatum & $5.04^{\mathrm{a}}$ & $54^{\mathrm{a}}$ & $2.72^{\mathrm{a}}$ & $1.40^{\mathrm{d}}$ & $2.98^{\mathrm{c}}$ \\
\hline \multirow{3}{*}{5.2} & NM & $5.08^{\mathrm{a}}$ & nd & nd & nd & nd \\
\hline & Gi. margarita & $5.12^{\mathrm{a}}$ & $53^{\mathrm{a}}$ & $2.71^{\mathrm{a}}$ & $2.46^{\mathrm{b}}$ & $5.54^{\mathrm{b}}$ \\
\hline & G. etunicatum & $5.05^{\mathrm{a}}$ & $56^{\mathrm{a}}$ & $2.70^{\mathrm{a}}$ & $2.23^{\mathrm{bc}}$ & $5.00^{\mathrm{b}}$ \\
\hline
\end{tabular}
soil $\mathrm{pH}$ in the hyphae compartment

" means within a column with different superscripts are significantly different based on LSD-test at p<0.05. NM: no mycorrhiza, MCRL: mycorrhizal colonized root length, nd: not detected.

\begin{tabular}{|c|c|c|c|c|c|c|}
\hline \multirow{2}{*}{$\begin{array}{c}\text { Initial soil } \\
\mathrm{pH}\end{array}$} & \multirow{2}{*}{ Inoculation } & \multirow{2}{*}{$\begin{array}{l}\text { Shoot DW } \\
\text { (mg/plant) }\end{array}$} & \multirow{2}{*}{$\begin{array}{c}\text { MGR } \\
(\%)\end{array}$} & \multicolumn{2}{|c|}{ Shoot-P } & \multirow{2}{*}{$\begin{array}{c}\text { MPR } \\
(\%)\end{array}$} \\
\hline & & & & $(\%)$ & (mg/plant) & \\
\hline \multirow[t]{3}{*}{4.6} & NM & $150^{\left.\mathrm{c}^{*}\right)}$ & na & $0.088^{\mathrm{c}}$ & $0.13^{\mathrm{c}}$ & na \\
\hline & G. margarita & $271^{\mathrm{a}}$ & 81 & $0.117^{\mathrm{a}}$ & $0.32^{\mathrm{a}}$ & 139 \\
\hline & G. etunicatum & $170^{\mathrm{bc}}$ & 13 & $0.105^{b}$ & $0.18^{\mathrm{bc}}$ & 35 \\
\hline \multirow[t]{3}{*}{4.9} & NM & $160^{\mathrm{bc}}$ & na & $0.084^{\mathrm{c}}$ & $0.13^{\mathrm{c}}$ & na \\
\hline & G. margarita & $264^{\mathrm{a}}$ & 65 & $0.119^{\mathrm{a}}$ & $0.31^{\mathrm{a}}$ & 130 \\
\hline & G. etunicatum & $183^{\mathrm{b}}$ & 14 & $0.118^{\mathrm{a}}$ & $0.25^{\mathrm{ab}}$ & 84 \\
\hline \multirow[t]{3}{*}{5.2} & NM & $166^{\mathrm{bc}}$ & na & $0.085^{\mathrm{c}}$ & $0.14^{\mathrm{c}}$ & na \\
\hline & G. margarita & $255^{\mathrm{a}}$ & 53 & $0.096^{\mathrm{bc}}$ & $0.25^{\mathrm{ab}}$ & 73 \\
\hline & G. etunicatum & $244^{\mathrm{a}}$ & 47 & $0.119^{\mathrm{a}}$ & $0.29^{a}$ & 98 \\
\hline
\end{tabular}

Table 2 Shoot growth and P content of cowpea plants and their responses to mycorrhiza

${ }^{*}$ Means within a column with different superscripts are significantly different based on LSD-test at p<0.05. NM: no mycorrhiza, DW: dry weight, MGR: mycorrhizal growth response, MPR: mycorrhizal p-uptake response, na: not applicable. 


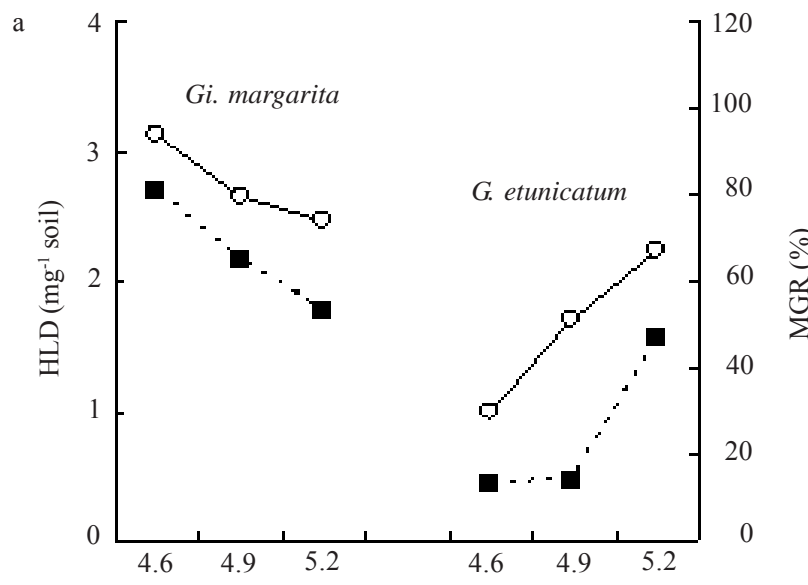

$\mathrm{b}$

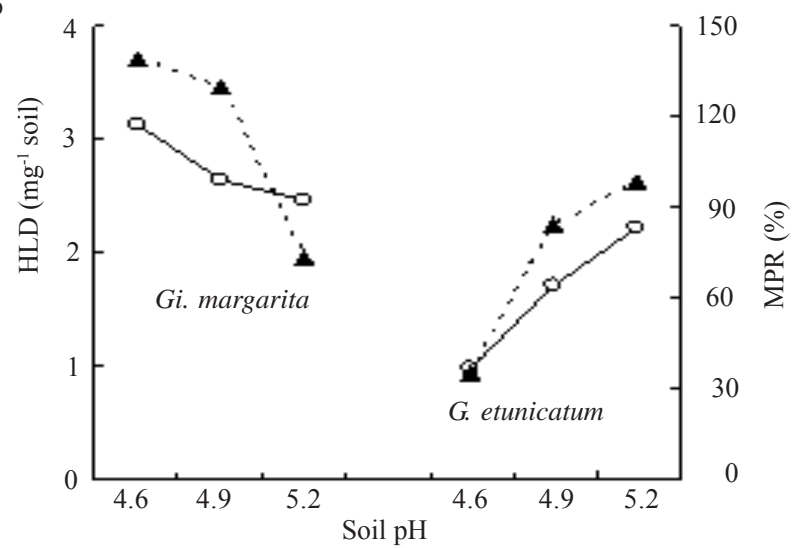

Fig 2 a, Mycorrhizal growth (MGR); and b, P-uptake responses (MPR) of cowpea plants to hyphal length density (HLD) of Gi. margarita and $G$. etunicatum at different soil $\mathrm{pH}$ levels in the HC; $\mathrm{HLD}=\mathrm{O} ; \mathrm{MGR}=; \mathbf{M P R}=\boldsymbol{\Lambda}$.

\section{DISCUSSION}

Results of the present study demonstrate that low soil $\mathrm{pH}$ significantly influenced growth of external hyphae of AM fungi with a consequence of their working to benefit growth of the host plants. These findings support the hypothesis of Robson and Abbott (1989) that high soil acidity in terms of excessive $\mathrm{H}^{+}$ion activities is one of the main factors limiting the growth and functioning of AM fungi in acidic soils.

Several stages in the life cycle of AM fungi such as the germination of spores, the elongation of germ tubes and the colonization of host plant roots are inhibited at low soil $\mathrm{pH}$ according to Green et al. (1976); Siqueira et al. (1985); and Clark (1997). However, due to inappropriate experimental methods, the toxic effects of excessive $\mathrm{H}^{+}$ions on the growth of the external fungal hyphae have not been described so far. Using pots divided in such a way as to have a special compartment for growing fungal hyphae separately from their host plant roots, this study found that the two AM fungi tested, G. margarita and G. etunicatum, exhibited different levels of external hyphal development. G. margarita produced external hyphae at a much higher rate than G. etunicatum. This indicates that although these two fungi formerly have been categorized as superior under acidic conditions, they basically need different acidity levels to develop an extensive network of hyphae in soils. G. margarita appears to be better adapted to low $\mathrm{pH}$ (4.6-5.2), whereas G. etunicatum required a pH 5.2 or higher. The production of hyphae formed in soils amongst MA fungi in general may vary considerably with their inherent characteristics (Abbott and Robson 1985) and responses to soil conditions (Wilson 1988). However, mechanisms of how these fungi resist the adverse soil conditions remain in question. The adequacy of energy supplied by host plants for the fungal hyphae to grow (Abbott et al. 1984), or the production of exudates by the hyphae (Bago et al. 1996) that may modify soil $\mathrm{pH}$ surrounding them, has been proposed. Results of the present study verifies in part the first mechanism by which better growth of host plants generates a greater length density of symbiotic fungal hyphae in soils or vice versa. However, my results did not support the second mechanism. I did not find any significant changes in observed $\mathrm{pH}$ level of bulk soils in the HC.

The present study also found that the two fungi significantly improved $\mathrm{P}$ uptake and growth of cowpea plants. This is further evidence on the importance of AM symbioses, particularly for plants encountering unfavorable conditions, such as low soil $\mathrm{pH}$. My results support recent work showing beneficial effects of AM on plant growth on acid soils (Yost and Fox 1979; Rohyadi et al. 1988; Nurlaeny et al. 1996; Clark and Zeto 2000).

In spite of the above facts, variation in AM effectiveness in acidic soils exists among fungal species (Clark 2002). G. margarita was found much more effective than $G$. etunicatum, as in our previous work (Rohyadi et al. 2004). However, the causes of the variation remain unknown. Most studies using conventional (non-compartmented) pots pointed out that the variation was a consequence of differences mainly in the intensity of root colonization (Nurlaeny et al. 1996; Clark et al. 1999; Clark 2002). Increased length (or percentage) of root colonization increased mycorrhizal effects on plant growth and $\mathrm{P}$ uptake. This was, however, not the case in the present study. As might be expected, using a growing system of compartmented pots, G. margarita and G. etunicatum extensively colonized cowpea plant roots and in the same way. However, they had different effects on the growth and P uptake of the plant. This indicates clearly that symbiotic effectiveness of these fungi was not related to either length or percentage of root colonization, but on other fungal-symbiont traits, mainly growth of external hyphae in soils. Therefore, in short, this study verified that the effectiveness of AM symbiosis on plant growth in acid soils is closely associated with the growth of external fungal hyphae rather than with root colonization. These findings also answer the question on the cause of the different responses of the cowpea plant to these AM fungi tested as reported previously (Rohyadi et al. 2004).

Some other studies employing compartmented pot systems have also been demonstrated the significant role of external hyphae in AM symbioses (Jakobsen et al. 1992; Smith et al. 2000; Van Aarle et al. 2002). These studies suggested that the fungal hyphae may function as the vital component for AM effectiveness. For example, Smith et al. (2000) counted that up to $80 \%$ of the total P taken up by mycorrhizal colonized plants was generated from the external hyphae of the fungus. It seems that the function of external fungal hyphae becomes more important for plants grown on 
acid soils since most of them have poorly developed root systems (Marschner 1991). Intensive growth of the hyphae from the inhibited roots may essentially compensate their limited access to resources of nutrients and water in soils.

Importantly, the results of this study increase our understanding of the detrimental effects of high soil acidity on various AM fungal activities. Excessive $\mathrm{H}^{+}$ions may negatively influence not only spore germination and germ tube growth, but also the development and distribution of external hyphae in the soil. As the external hyphae of the fungi are themselves subject to the negative effects of soil acidity, effectiveness of AM symbioses at low soil $\mathrm{pH}$ may depend on their fungal component's ability to withstand the adverse conditions in growing external hyphae. Consequently, changes in soil $\mathrm{pH}$ affecting the growth of the hyphae may also affect plant responses to the symbioses. Therefore, a species or isolate of AM fungus which has the characteristic of an extensive hyphal network would seem to be an excellent candidate for inoculation purposes in acid soils. This study verified that G. margarita is tolerant to low $\mathrm{pH}$, thereby it could be considered as one possible candidate.

\section{REFERENCES}

Abbott LK, Robson AD. 1985. The effect of soil pH on the formation of vesicular arbuscular mycorrhiza by two species of Glomus. Aus $J$ Soil Res 23:235-261.

Abbott LK, Robson AD, de Boer G. 1984. The effect of phosphorus on the formation of hyphae in soil by vesicular-arbuscular mycorrhizal fungus Glomus fasciculatum. New Phytol 97:437-446.

Bago B, Vierheilig H, Piché Y, Azcón-Aguilar C. 1996. Nitrate depletion and $\mathrm{pH}$ changes induced by the extraradical mycelium of the arbuscular mycorrhizal fungus Glomus intraradices in monoxenic culture. New Phytol 133:273-280.

Borie F, Rubio R. 1999. Effects of arbuscular mycorrhizae and liming on growth and mineral acquisition of aluminium tolerant and aluminium sensitive barley cultivars. J Plant Nut 22:121-137.

Clark RB. 1997. Arbuscular mycorrhizal adaptation, spore germination, root colonization, and host plant growth and mineral acquisition at low pH. Plant Soil 192:15-35.

Clark RB. 2002. Differences among mycorrhizal fungi for mineral uptake per root length of switchgrass grown in acidic soil. J Plant Nut 28:1753-1772.

Clark RB, Zeto SK. 2000. Mineral acquisition by arbuscular mycorrhizal plants. J Plant Nut 23:867-902.

Clark RB, Zeto SK, Zobel RW. 1999. Arbuscular mycorrhizal fungal isolate effectiveness on growth and root colonization of Panicum virgatum in acidic soil. Soil Biol Biochem 31:1757-1763.

Close EA, Powell HKJ. 1989. Rapidly extracted (0.02 $\mathrm{M} \mathrm{CaCl}_{2}$-soluble) 'reactive' aluminium as a measure of aluminium toxicity in soils. Aus J Soil Res 27:663-672.

Giovannetti M, Mosse B. 1980. An evaluation of techniques for measuring vesicular-arbuscular mycorrhizal infection in roots. New Phytol 84: 489-500
Green WE, Graham SO, Schenck NC. 1976. The influence of $\mathrm{pH}$ on the germination of vesicular arbuscular mycorrhizal spores. Mycologia 68:929-934.

Jakobsen I, Abbott LK, Robson AD. 1992. External hyphae of vesiculararbuscular mycorrhizal fungi associated with Trifolium subterraneum L. 1. Spread of hyphae and phosphorus inflow into roots. New Phytol 120:371-380.

Manjunath A, Habte M. 1991. Root morphological characteristics of host species having distinct mycorrhizal dependency. Can $\mathrm{J} B o t$ 69:671-676.

Marschner H. 1991. Mechanisms of adaptation of plants to acid soils. Plant Soil 134:1-20.

Nurlaeny N, Marschner H, George E. 1996. Effects of liming and mycorrhizal colonization on soil phosphate depletion and phosphate uptake by maize (Zea mays L.) and soybean (Glycine max L.) grown in two tropical acid soils. Plant Soil 181: 275-285.

Phillips JM, Hayman DS. 1970. Improved procedures for clearing roots and staining parasite and vesicular arbuscular mycorrhizal fungi for rapid assessment on infection. Trans Br Mycol Soc 55:158161 .

Rayment GE, Higginson FR. 1992. Australian Laboratory Handbook of Soil and Water Chemical Methods. Melbourne: Inkata Pr.

Robson AD, Abbott LK. 1989. The effect of soil acidity on microbial activity in soils. In: Robson AD (ed). Soil Acidity and Plant Growth. Sydney: AP. p 139-166.

Rohyadi A. 2003. Effects of aluminium on arbuscular mycorrhizal symbioses in cowpea plant growth [Ph.D Thesis]. Adelaide: University of Adelaide.

Rohyadi A. 2006. Elevated aluminium concentrations in soil reduce growth and function of external hyphae of Gigaspora margarita in growth of cowpea plants. Bionatura 8:47-59.

Rohyadi A, FA Smith, Murray RS, Smith SE. 2004. Effects of $\mathrm{pH}$ on mycorrhizal colonization and nutrient uptake in cowpea under conditions that minimise confounding effects of elevated available aluminium. Plant Soil 260:283-290.

Rohyadi A, Modjo HS, Radjagukguk B. 1988. The effects of arbuscular mycorrhiza on growth of maize on the Red Yellow Podzolic soil (in Indonesian). J BPPS-UGM 2:155-162.

Schüßler A, Schwarzott D, Walker C. 2001. A new fungal phylum, the Glomeromycota: phylogeny and evolution. Mycol Res 105: 4131421.

Siqueira JQ, Sylvia DM, Gibson J, Hubbell DH. 1985. Spores, germination, and germ tubes of vesicular arbuscular mycorrhizal fungi. Can J Microbiol 3:1965-1971.

Smith FA, Jakobsen I, Smith SE. 2000. Spatial differences in acquisition of soil phosphate between two arbuscular mycorrhizal fungi in symbiosis with Medicago truncatula. New Phytol 147:357-366.

Smith GS, Johnston CM, Cornforth IS. 1983. Comparison of nutrient solutions for growth of plants in sand culture. New Phytol 94:537548 .

Van Aarle I, Olsson PA, Söderström B. 2002. Arbuscular mycorrhizal fungi respond to the substrate $\mathrm{pH}$ of their extraradical mycelium by altered growth and root colonization. New Phytol 155:173-182.

Wilson DO. 1988. Differential plant response to inoculation with two VA mycorrhizal fungi isolated from a low-pH soil. Plant Soil 110:69-75.

Yost RS, Fox RL. 1979. Contribution of mycorrhizae to P nutrition of crops growing on an Oxisol. Agronomy 71:903-908. 